\title{
Desafios para a inserção e permanência dos alunos nas empresas vinculadas ao Programa Jovem Aprendiz do Senac Chapecó, SC
}

\section{Challenges for the insertion and permanence of students in companies linked to Senac Young Apprentice Program (Programa Jovem Aprendiz do Senac) in Chapecó, SC}

\author{
Janaína Daudt dos Santos Mestre em Políticas Sociais e Dinâmicas Regionais (Unochapecó). Serviço Nacional de \\ https://orcid.org/0000-0002-1564-0911 Aprendizagem Comercial (Senac) - Brasil. janainadaudt@gmail.com \\ Márcia Luíza Pit Dal Magro Doutora em Psicologia. Universidade Comunitária da Região de Chapecó (Unochapecó) - Brasil. \\ http://orcid.org/0000-0002-2127-9261 mapit@unochapeco.edu.br \\ Andressa Morgan Mestre em Administração (Unoesc). Serviço Nacional de Aprendizagem Comercial (Senac) - \\ https://orcid.org/0000-0003-1544-8978 Brasil.dressamorgan@hotmail.com
}

\section{RESUMO}

O Programa Jovem Aprendiz (PJA) integra políticas públicas voltadas à educação profissionalizante, sendo ofertado pelo sistema $S$ em parceria com as empresas, e já possibilitou a formação e inserção profissional de milhares de jovens em todo o país. As formas como as empresas se organizam para receber e manter os jovens durante o PJA, é parte fundamental do processo de educação profissional. Esta pesquisa teve como objetivo analisar o processo de inserção e permanências dos jovens nas empresas, com vistas à qualificação do Programa Jovem Aprendiz, ofertado pelo Senac no município de Chapecó, Santa Catarina. Como metodologia, foi utilizada a pesquisa-ação, sendo composto Grupo Estratégico de Trabalho (GET). Este contou com professores e gestores do PJA e com representantes de empresas participantes do Programa, e contribuiu com as diferentes etapas do estudo. Foram realizados encontros de discussão com o GET e aplicado questionário junto às empresas que recebem os jovens. $\mathrm{O}$ estudo foi realizado durante o ano de 2020. Os resultados apontam que a inserção e permanência dos jovens nas empresas, compreende realidades muito distintas. Isso inclui desde a realização de processos de seleção e integração, assim como suporte para a permanência dos alunos, até contextos em que a presença dos jovens é vista como mera obrigação legal, e/ou em que não há estratégias para auxiliar o ingresso e permanência desses. Entre as propostas para qualificar o PJA, se destaca a necessidade de melhorar a comunicação e aproximação entre empresas, Senac e famílias, para o quê o Professor de Vivências, figura presente no Senac do município, poderia desempenhar função estratégica.

Palavras chaves: Programa Jovem Aprendiz; educação profissional; Senac.

\section{ABSTRACT}

The Young Apprentice Program (Programa Jovem Aprendiz -PJA) integrates public policies aimed at professional education, being offered by the $S$ system in partnership with companies, and it has already enabled the training and professional insertion of thousands of young people across the country. The ways that the companies organize themselves to receive and maintain young people during the PJA, is a fundamental part of the professional education process. This research aims to analyze the process of insertion and permanence of young people in companies, with a view to qualifying the Young Apprentice Program (Programa Jovem Aprendiz), offered by Senac in the municipality of Chapecó, Santa Catarina. As a methodology, action research was used, comprising the Strategic Working Group (SWG). It included teachers and managers from PJA and representatives of companies participating in the Program, which contributed to the different stages of the study. The study was carried out during the year 2020. Discussion meetings were held with the SWG and a questionnaire was also applied to companies that receive these youngsters. The results show that the insertion and permanence of young people in companies comprises very different realities ranging from carrying out selection and integration processes, as well as support for their permanence, to contexts in which the presence of young people is seen as a mere legal obligation, and / or in which there are no strategies to assist their entry and permanence in the companies. Among the proposals to qualify the PJA, the need to improve communication and rapprochement between companies, Senac and families. For that purpose, the teacher of Experiences, a professional present in the Senac of the municipality, could play a strategic role.

Key Words: Young Apprentice Program (Programa Jovem Aprendiz); professional education; Senac. 


\section{INTRODUÇÃO}

De acordo com Neri (2014), entre os anos 1995 a 2004, a taxa de desemprego entre os jovens chegou a atingir $18 \%$ e a da informalidade $51,7 \%$. Essa realidade melhora a partir de 2000 , para o que também contribui a promulgação da Lei da Aprendizagem e de investimentos maciços do governo federal na educação profissional, o que leva à ampliação dos cursos profissionalizantes gratuitos, e vinculados à escolarização formal (CASTRO; AQUINO; ANDRADE, 2009). Nesse sentido, Neri (2014) destaca que desde 2004, a frequência dos jovens à educação profissional aumentou $83 \%$.

De acordo com Villar e Mourão (2018), os jovens que conseguem ingressar no Programa de Aprendizagem o avaliam como uma boa oportunidade para entrar no mercado de trabalho, sendo que esta caracteriza, com frequência a primeira experiência profissional dos jovens. Sobre isso, Pochmann (2007, p. 13) aponta que esse "representa um momento decisivo para a trajetória futura do jovem no mercado de trabalho. Quanto melhor forem as suas condições de acesso ao primeiro emprego, proporcionalmente mais favorável deverá ser a sua evolução profissional".

A política de aprendizagem cria oportunidades tanto para o aprendiz quanto para as empresas, pois prepara o jovem para desempenhar atividades profissionais e ter capacidade para lidar com diferentes situações no mercado de trabalho. Ao mesmo tempo, permite às empresas formarem força de trabalho qualificada, cada vez mais necessária em um cenário econômico em permanente transformação social e tecnológica (SINAIT, 2019).

O Programa Jovem Aprendiz (PJA), ofertado pelo Sistema S, está voltado à educação profissional de jovens entre 14 a 24 anos, com vistas a sua inserção qualificada no mercado de trabalho. Com base no artigo 429 da Consolidação das Leis do Trabalho (CLT), os jovens que exercem o trabalho de aprendizes nas empresas do comércio devem desenvolver sua formação em parceria com o Serviço Nacional de Aprendizagem Comercial (Senac). Este tem como objetivo orientar, ensinar e acompanhar o desempenho do jovem aprendiz no desenvolvimento de suas atividades.

Desde sua criação em 2005, o Programa Jovem Aprendiz já teria contratado mais de 3 milhões de jovens no país (GALDINO, 2018). Segundo os dados da secretaria institucional do Senac Chapecó, essa unidade implementou o Programa Jovem Aprendiz no ano de 2003 e, até o segundo semestre de 2018, capacitou aproximadamente 4.000 aprendizes, cerca de 525 alunos por ano. $O$ número expressivo de jovens que frequentam essa modalidade de educação profissional indica a importância do PJA para o cenário nacional e regional.

Considerando que as formas como as empresas se organizam para receber e manter os jovens durante o PJA, é parte fundamental do processo de educação profissional, delineou-se como objetivo deste estudo analisar o processo de inserção e permanências dos jovens nas empresas, com vistas à qualificação do Programa Jovem Aprendiz ofertado pelo Senac no município de Chapecó, Santa Catarina. O PJA foi implementado no referido município no ano de 2003, sendo que até 2018 atendeu aproximadamente 4.000 alunos, envolvendo mais de 100 empresas parceiras.

\section{MÉTODO}

Este estudo se caracteriza como uma pesquisa-ação, a qual tem fundamento na abordagem participativa. Tripp (2005, p. 445) traz que a pesquisa-ação "é um termo genérico para qualquer processo que siga um ciclo no qual se aprimora a prática pela oscilação sistemática entre agir no campo da prática e investigar a respeito dela".

Para Dionne (2007), ao executar a pesquisa-ação, é necessário um planejamento de quatro etapas denominado de ciclo de intervenção planejada, sendo as quatro fases: 1) Identificação das situações iniciais, 2) Projeção das ações, 3) Realização das atividades previstas e 4) Avaliação dos resultados obtidos. Estas etapas foram consideradas para planejar esta investigação-ação. 
A pesquisa, realizada durante o ano de 2020, contou com a participação de três gestores do setor de Recursos Humanos das empresas vinculadas ao Senac pelo Programa Jovem Aprendiz (identificados como G1, G2 e G3), cinco professores do PJA (identificados como P1, P2, P3, P4 e P5), um coordenador (identificado como C1) do Programa vinculado ao Senac e duas pedagogas (identificados como Ped 1 e Ped 2). Esses participantes formaram o Grupo Estratégico de Trabalho (GET), que teve participação ativa em todo o processo de investigação e desenvolveu a identificação das temáticas, a avaliação dos resultados e a elaboração de propostas de ação.

Quanto aos professores do PJA que participaram da ação, estes foram responsáveis pela disciplina denominada "Unidade Curricular da Prática Profissional de Aprendizagem", que consta no plano de curso do Senac. O professor ministra essa Unidade Curricular por meio de acompanhamento da prática do aprendiz nas empresas, sendo este denominado Professor de Vivência. Ele acompanha todo o processo de inserção, desenvolvimento das atividades e avaliação do jovem tanto nas empresas quanto no Senac.

Já no primeiro encontro do GET, realizado em fevereiro de 2020, foi promovida uma discussão, por meio do uso da técnica do Café Mundial. Esta "[...] vem sendo utilizada em vários países com o objetivo de potencializar diálogos e viabilizar a construção coletiva de proposições em torno de temas relevantes nos diversos campos de conhecimento" (MACHADO; PASSOS, 2018, p. 1). Para tanto, foram feitas perguntas em torno dos temas: seleção e integração, permanência e desligamento no processo de funcionamento do PJA, observando-se as potencialidades e fragilidades indicadas pelos participantes.

Neste dia, participaram, presencialmente, quatro professores do Senac e uma gestora de Recursos Humanos, sendo que as outras duas gestoras colaboraram com os temas enviando suas contribuições de modo escrito, já que não puderam comparecer ao encontro.

As discussões realizadas no primeiro encontro do GET subsidiaram a elaboração de um questionário para as empresas parceiras do Senac Chapecó no PJA. O questionário apresentado contou com 28 perguntas relacionadas aos temas anteriormente propostos e, posteriormente, foi encaminhado para validação do GET. Após validado, o questionário foi enviado para as 113 empresas conveniadas ao PJA, cuja resposta se dava por meio do Google Docs.

Depois de enviados os questionários, foi realizado contato telefônico com todas as empresas a fim de sensibilizar as mesmas para responder ao instrumento. O questionário ficou disponível durante um período de quatro meses (Fevereiro a Maio de 2020), sendo que 18 empresas responderam o mesmo.

A análise qualitativa e quantitativa das respostas, bem como a síntese do primeiro encontro do GET, subsidiou o material utilizado no segundo encontro. Ele teve como objetivo principal reconhecer ações exitosas com vistas à inserção, permanência e desligamento dos aprendizes, bem como discutir possibilidades de enfrentamento às problemáticas identificadas sobre o PJA em relação aos temas propostos. Neste dia, o encontro aconteceu de maneira on-line, através da plataforma do Google Meet, em função da exigência do distanciamento social provocada pela pandemia de Covid-19.

Na ocasião, foi utilizada a ferramenta Design Thinking, a qual se caracteriza como metodologia participativa, que visa a resolução de problemas complexos, centrada no ser humano, baseada em empatia, colaboração e experimentação. As principais etapas desta abordagem visam: a) descobrir (identificar) problemas, por meio da pesquisa, b) definir o foco do problema, c) desenvolver soluções e d) entregar a elaboração do protótipo com a solução e receber feedback (BIOLCHINI; PIMENTA; OROFINO, 2012). É importante ressaltar que estes passos foram adequados, para serem utilizados de modo on-line.

Neste segundo encontro, participaram novamente quatro professores do Senac, duas gestoras de Recursos Humanos, duas pedagogas e a coordenadora do PJA.

O terceiro e último encontro do GET foi realizado a fim de apresentar a sistematização e validar as ações propostas, e contou com a participação de duas pedagogas, uma gestora de $\mathrm{RH}$, uma professora e a coordenadora do Programa Jovem Aprendiz. O encontro ocorreu por meio da ferramenta Google Meet. Na ocasião o grupo analisou a sistematização das sugestões para qualificar o Programa. Destaca-se que além das estratégias de pesquisa descritas, a observação participante feita por uma das autoras na condição de professora do PJA também iluminou as análises realizadas ao longo de dois anos. 


\title{
3 INSERÇÃO DO JOVEM APRENDIZ NAS EMPRESAS
}

A inserção dos jovens aprendizes nas empresas se dá de diferentes formas, as quais são permeadas pelas distintas realidades das organizações que os recebem. As observações do campo apontam essa como uma etapa importante para a permanência do jovem. Nesse sentido, se buscou analisar como se dá esse processo de inserção e como o mesmo pode ser aperfeiçoado a fim de qualificar o PJA, considerando que esta etapa envolve o processo de seleção e integração do jovem.

Entre os modos de inserção de trabalhadores nas empresas, o processo de recrutamento e seleção de pessoas é considerado uma ferramenta de gestão essencial para o bom desempenho organizacional, como apontam Pereira e Spíndola (2020). Esse processo busca "encontrar pessoas capacitadas a desempenharem as tarefas inerentes à rotina de trabalho, de forma eficiente e eficaz, a fim de obter resultados otimizados na operação empresarial" (PRATO NETO et al., 2016, p. 1.). Ferreira e Soeira (2013) apontam que esse processo precisa ser precedido de descrição e análise de cargos, o que orienta o recrutamento e seleção.

A fase do recrutamento visa trazer candidatos potencialmente qualificados e capazes de preencher cargos e oferecer qualificações para a organização (CHIAVENATO, 2009). Já a seleção, de acordo com Lacombe (2005), tem como objetivo escolher, entre os candidatos disponíveis, aqueles cujo perfil seja mais adequado para a vaga a ser preenchida, tendo em vista as condições de se ajustar à empresa e ao cargo e conseguir demonstrar um bom desempenho.

Em relação à seleção do jovem pelas empresas, o Manual de Aprendizagem traz que:

\begin{abstract}
O empregador dispõe de total liberdade para selecionar o aprendiz, desde que observado o princípio constitucional da igualdade e a vedação a qualquer tipo de discriminação atentatória aos direitos e liberdades fundamentais, bem como a observância aos dispositivos legais pertinentes à aprendizagem e a prioridade conferida aos adolescentes na faixa etária entre 14 e 18 anos, além das diretrizes próprias e as especificidades de cada programa de aprendizagem profissional (SINAIT, 2019, p. 15).
\end{abstract}

É importante considerar que para muitos jovens, a inserção laboral promovida pelo PJA é primeira experiência no mercado de trabalho (PEREIRA; SPÍNDOLA, 2020). Nesse sentido, o processo de seleção tende a elucidar mais sobre o perfil do jovem em relação às atividades oferecidas pela empresa, do que sobre sua trajetória profissional anterior.

Das empresas pesquisadas, $50 \%$ dizem fazer processo de recrutamento e seleção dos jovens aprendizes, 27,8\% contratam os jovens a partir da indicação de terceiros (clientes ou funcionários) e 22,3\% não têm formas de inserção padronizadas, ou seja, efetuam a contratação dos jovens sem processo seletivo ou indicação, não apresentando nenhum critério pré-definido.

Diversas técnicas para o processo de seleção podem ser aplicadas, como os testes técnicoprofissionais, testes psicológicos, dinâmicas e entrevista com gestor do candidato. Mas, uma boa seleção, segundo Lacombe (2005, p. 79), "costuma considerar não só a vaga atual, mas o potencial do candidato". Os resultados da pesquisa apontam que embora algumas empresas se utilizem de processos de seleção mais elaborados, como, por exemplo, uso de testes, as entrevistas ainda são os métodos mais utilizados para seleção dos jovens.

Destaca-se que o cargo para a vaga de jovem aprendiz não requer experiências. Nesse sentido, o Manual de Aprendizagem, do Governo Federal, aponta que:

\footnotetext{
[...] é assegurada aos adolescentes na faixa etária entre 14 e 18 anos prioridade na contratação para o exercício da função de aprendiz, salvo quando: I- as atividades práticas de aprendizagem ocorrerem no interior do estabelecimento, sujeitando os aprendizes à insalubridade ou à periculosidade, sem que se possa ilidir o risco ou realizá-las integralmente em ambiente simulado; II - a lei exigir, para o desempenho das atividades práticas, licença ou autorização vedada para pessoa com idade inferior a 18 anos; e III - a natureza das atividades práticas for incompatível com o desenvolvimento físico, psicológico e moral dos adolescentes aprendizes. (BRASIL, 2011, p. 14).
}

Ao avaliarem o processo de inserção dos jovens aprendizes, $66,7 \%$ das empresas dizem não ter dificuldade nessa etapa e $33,3 \%$ assumem ter dificuldades para selecionar os jovens aprendizes. Essa dificuldade pode ter relação com a não realização de processo de recrutamento e seleção, indicando que 
profissionalizar esta etapa do processo poderia contribuir com a inserção e permanência dos jovens nas empresas.

Em relação ao Programa Jovem Aprendiz, uma das questões que as observações do campo pesquisado indicam, é que pela contratação desses jovens se tratar de uma exigência legal, muitas empresas não têm, a priori, a demanda de um cargo para os mesmos, o que pode impactar no processo de recrutamento, seleção e integração, e produzir desafios tanto para as organizações quanto para os jovens que se inserem nas mesmas. Como expressa a gestora de RH: "Não temos o hábito de contratar [referindo-se ao término do programa] o Jovem Aprendiz, pois contratamos devido a obrigação" (E4). Já, outra gestora de RH pondera fazendo um contraponto: "Considero o projeto [referindo-se ao PJA] bom, desde que pensemos nesses jovens como futuros profissionais para nossa empresa e não apenas para cumprir cota" (E3).

No estudo de Matsuzaki (2011), observa-se que a obrigatoriedade do PJA também oferece oportunidades às empresas para qualificarem seus processos produtivos. Em seu estudo o autor aponta que:

Havia uma necessidade oculta e com a chegada dos aprendizes a empresa conseguiu perceber o potencial que os jovens poderiam contribuir para diversas atividades de apoio, como por exemplo: organização de documentos, auxílio em manter controles financeiros, de estoque e produtos atualizados em sistema (MATSUZAKI, 2011, p. 101).

Uma das empresas pesquisadas opta pela contratação de jovens que já participam de outros programas sociais promovidos pelo Estado ou ONGs, o que vai ao encontro da realidade estudada por Pessoa (2017). De acordo com a gestora de RH, a maior vulnerabilidade social e necessidade de ter renda desses jovens, bem como a perspectiva de contratação futura, contribui para o processo da inserção deles na empresa:

Faço a seleção desde o início do projeto do Jovem aprendiz na ONG (diz nome da ONG) e tenho tido êxito nas contratações, permanências e efetivação dos jovens. Percebo que pela necessidade social/financeira, esses jovens valorizam a oportunidade e se empenham para fazer um bom estágio, pois querem uma oportunidade futura na empresa (E1)

A percepção da gestora é corroborada pelo debate do GET, que aponta que os jovens que apresentam mais necessidade de recursos financeiro para ajudar a família, comprometem-se mais com o Programa.

Já, outro gestor de RH destaca que observa predomínio da falta de vontade e do descomprometimento do jovem com o trabalho, o que é apontado como empecilho para o processo de contratação dos mesmos: "A seleção de jovens aprendizes é bem complicada, pois é difícil encontrar jovem com vontade de crescer na empresa, em geral já vem para a entrevista sem vontade" (E2).

Para melhor lidar com as dificuldades que envolvem a inserção dos jovens no espaço de trabalho, as empresas desenvolvem estratégias no processo de seleção com vistas a escolher entre os jovens, os melhores candidatos para a organização, por meio de ações como ter uma conduta diferenciada com o jovem já na entrevista, como indica a gestora de RHE1:

Na grande maioria das contratações não temos queixas. Percebo que, por serem jovens e estarem passando por muitas transformações da adolescência, às vezes, as mídias sociais atrapalham um pouco, por isso a conduta da empresa deve ser rígida desde o início da contratação, deixar bem claro as normas desde o início e, mesmo assim, vez em quando, no momento do feedback, retomar esta questão (E1).

Outras empresas participantes do estudo apostam no diálogo e no envolvimento dos pais dos jovens no processo da seleção e contratação, como afirma a gestora: "Entrevista com os pais acompanhado do jovem, apresentação dos setores da empresa juntamente da explicação de como vai ser o trabalho do jovem na empresa" (E3). Na mesma direção, diz outro gestor de RH:

O diálogo é primordial. Sempre procuramos conversar com os jovens e pais para alinharmos o processo, o apoio familiar e acompanhamento dos pais durante o processo de seleção é de grande relevância, pois os jovens procuram se comprometer para não decepcionar os pais e gestores (E4). 
Como mencionado anteriormente, algumas empresas buscam jovens por indicação. É o que relata a E5: "Nossas experiências com jovens indicados aumentam a permanência na empresa". Essa afirmação sugere que, pela experiência desse gestor de $\mathrm{RH}$, o jovem que tem algum parente ou cliente na empresa em que atua demonstra um desempenho melhor. Em contraposição, E1 avalia que a atuação do jovem indicado pode levar a um acompanhamento excessivo ou até mesmo interferência no decorrer do programa, deixando o responsável pelo jovem constrangido ao realizar eventuais advertências e feedbacks.

Durante o segundo encontro do GET, discutiu-se qual seria o processo de seleção mais eficaz, com intuito de selecionar o perfil mais adequado com vistas ao melhor aproveitamento dessa oportunidade de trabalho, tanto pelo o jovem quanto pela instituição que o emprega. Para qualificar esse processo, sugere-se, entre outras questões, o esclarecimento do jovem já na contratação, sobre as atividades que vai desenvolver, sendo relevante a empresa também ter esse conhecimento para direcionar o aprendizado prático do jovem. Mas, para que isso aconteça, a empresa precisa descrever/explicar a função jovem aprendiz e as suas atribuições.

É importante ressaltar que o conhecimento da empresa em relação às atividades que o jovem aprendiz pode desenvolver, referenciadas no Cadastro Brasileiro de Ocupações (CBO), pode favorecer a descrição do cargo de jovem aprendiz, bem como a atribuição de tarefas adequadas a esse. Com base nas observações de campo, verifica-se que, muitas vezes, os jovens aprendizes são encaminhados a fazer atividades não permitidas para esse público, como por exemplo: fazer entregas em espaços exteriores à empresa, atuar no caixa, receber ou entregar dinheiro, trabalhar com máquinas que oferecem risco de acidente, carregar peso acima do permitido, utilizar produtos químicos para limpeza, entre outros. Nessa direção, Pfaffenseller (2014, p. 18) destaca que "percebemos [...], que muitos dos direitos destes adolescentes e jovens continuam sendo violados, mesmo quando inseridos em Programas de Aprendizagem regulados pela Legislação Federal". Isso indica a importância de as organizações conhecerem as tarefas permitidas para o jovem aprendiz, de acordo com a CBO, bem como o perfil de conclusão de curso definido pelo Senac.

Durante as discussões do GET, chamou-se a atenção para o fato de que o processo de contratação dos jovens aprendizes precisa contar com o envolvimento do próprio Senac e das famílias do jovem, extrapolando a relação jovem empresa:

A empresa deveria explicar as tarefas do trabalho com amparo da CBO. Também teriam que ter esse conhecimento os professores de vivência do Senac e familiares... informar as atividades que serão desenvolvidas, descrevendo as atividades e seu objetivo. Mostrando a CBO, ela diferencia uma atividade da outra (P1).

O professor responsável pelo acompanhamento do jovem no Senac, conhecido como Professor de Vivência, deve mediar o processo de inserção do jovem aprendiz na empresa, por meio do esclarecimento acerca da lista de atividades possíveis ao jovem. Esta lista é baseada na área de negócio da empresa (supermercado, vendas ou administrativa) e está de acordo com o que Catálogo Nacional de Aprendizagem (CONAP) determina. Ela é útil no momento de descrever as atribuições do cargo e deve, também, ser informada ao jovem e a seus pais na ocasião da contratação.

Outro aspecto importante na inserção do jovem aprendiz nas empresas é o processo de integração. Essa refere-se a uma fase inicial, para realizar orientações ao novo funcionário, com vistas à aprendizagem sobre as rotinas de trabalho, bem como para conhecer a cultura e o funcionamento da organização.

Os primeiros dias de trabalho em uma organização sempre são pontuados por momentos de maior ou menor ansiedade. É natural que o novo colaborador necessite de algum tempo para ambientar-se, conhecer o local de trabalho e as pessoas com quem irá conviver, as normas da organização etc. Assim, quando um novo colaborador ingressa em uma organização, é preciso que se crie uma boa relação entre ambos e isso pode ser alcançado por meio acolhimento e do processo de integração (DELVAS, 2017, p. 37).

Já, para Lacombe (2005), a integração consiste na apresentação dos objetivos da empresa, das normas, das práticas, do horário de trabalho, dos serviços de apoio e atitudes e comportamentos esperados. 
Outro fator importante para realizar a integração é a socialização, momento em que há a apresentação aos colegas e das práticas culturais da empresa.

Lacombe $(2005$, p. 95) aponta que "um bom programa de integração também pode contribuir para encontrar posicionamento mais adequado para cada recém-admitido, contribuindo para otimizar o aproveitamento pessoal". No entanto, de acordo, com Porto e Soares (2019), muitas empresas não se preocupam em fazer ações de integração com o jovem aprendiz.

Matsuzaki (2011) destaca a importância de realizar a integração dos jovens aprendizes junto aos funcionários e chefias, pois, trata-se frequentemente do primeiro emprego para os jovens, o que marca a inserção desses no mercado de trabalho. Portanto, uma boa integração pode fazer a diferença e, inclusive, culminar em maiores chances de efetivação. Das empresas pesquisadas, $77,8 \%$ dizem realizar processo de integração do jovem aprendiz e 22,2\% não o realizam.

A necessidade de realizar o processo de integração é evidenciada a partir das questões indicadas no grupo do GET, como expressa a fala do P2:

O jovem tem dificuldade de saber qual é a função dele. Ele deveria ter clareza da função que vai desempenhar, assim, o processo de integração já começaria na assinatura do contrato... entendendo seus benefícios e salário (P2).

E1 também argumenta que: "Às vezes os jovens não sabem nada. Eles precisariam conhecer o programa melhor, entender o perfil profissional". Nesse sentido, Porto e Soares (2019) apontam que "para o jovem nada é óbvio, como o horário que ele precisa chegar ou como cumprimentar as pessoas. $O$ jovem precisa ser capacitado nos mínimos detalhes" ( $p$. 25). Para tal, os autores apontam ser necessário alguém na empresa preparado para acolhê-lo, que conheça a Lei da Aprendizagem, bem como que considere o perfil com que ele chega à organização.

O estudo de Matsuzaki (2011) concluiu que, na maioria das empresas contratantes, a inserção do jovem é bem assimilada pelo $\mathrm{RH}$. Todavia, nem sempre é bem recebida pelos gestores. Segundo o autor, isso pode se dar por desconhecimento da Lei da Aprendizagem, já que, muitas vezes, é solicitado ao jovem resultados de produtividade, ao que nem sempre esses estão preparados a corresponder. Em algumas situações, são desconsiderados fatores, tais como a falta de experiência profissional e a idade.

Para que o jovem comece a adquirir experiência é necessário que ele tenha capacitações. Sobre as atividades realizadas pelas empresas, que fazem processo de integração do jovem aprendiz participantes do estudo, estas compreendem treinamentos/capacitações (55,6\%), apresentação da empresa, setores e funcionários (72,2\%), apresentação das tarefas e suas finalidades $(66,7 \%)$ e outras $(5,6 \%)$. É observado, assim, que a maioria das empresas pesquisadas buscam desenvolver mais de uma atividade a fim de promover maior integração dos jovens.

A integração tem a intenção de ambientar o jovem aprendiz, desde o momento da contratação, à realidade da empresa. Sobre isso, avalia o P3: "Quando o jovem se sente acolhido, as chances de desenvolver um bom trabalho ou ser contrato aumentam". Isso é corroborado pelo estudo de Porto e Soares (2019), que aponta que muitos desligamentos ou desistências dos jovens ocorrem por não haver um bom acolhimento no momento da inserção na empresa. Isso se dá, muitas vezes, por falta de habilidade dos gestores na relação interpessoal ou pela não valorização da presença do jovem aprendiz na organização. Assim, o momento de integração pode ajudar nesse processo de acolhimento do jovem no espaço laboral.

Compreende-se que faz parte de um bom processo de integração ajudar o jovem aprendiz a entender a finalidade das tarefas que executará, a fim de que esse compreenda sua relevância na empresa. Para Silva, Nascimento e Botelho $(2013$, p. 5) "o sucesso do Programas de Integração facilita a identificação dos novos colaboradores com os valores e objetivos organizacionais, corroborando para o uso desta técnica como um mecanismo estratégico em gestão de pessoas".

Também é fundamental que o jovem aprendiz seja orientado sobre como executar as tarefas, para que aprenda a fazer isso de modo correto. As tarefas determinadas para o jovem aprendiz do PJA do Senac Chapecó vão depender do eixo do programa de aprendizagem em que atuará, sendo que o Senac apresenta 
três: 1) Aprendizagem Profissional Comercial em Serviços de Supermercado, 2) Aprendizagem Profissional Comercial em Serviços Administrativos e 3) Aprendizagem Profissional Comercial em Serviços de Vendas.

Conforme Pessoa (2017), os jovens entram motivados pela expectativa de aprendizagem de uma profissão, visualizada como emprego real. Nesse sentido, a adequação do jovem às novas formas de trabalho, as expectativas contidas em relação aos novos desafios e os benefícios da resolução desses desafios, promove melhor entendimento dos objetivos organizacionais e, assim, melhor desempenho do jovem. Isso foi corroborado pelas discussões do GET, em que se apontou: "Quando não tem desafio, a postura fica inadequada. Não vai rendendo, né? Vai desmotivando o aluno. Quando dá mais responsabilidade, eles começam a adquirir mais confiança" (P2).

No primeiro encontro do GET, foram levantadas algumas formas possíveis de se fazer a integração com os jovens aprendizes, tais como: iniciar com tarefas fáceis e, posteriormente, ir agregando maior dificuldade a estas. A importância da complexidade progressiva das tarefas para o processo de aprendizagem do jovem também é indicada pelo Manual da Aprendizagem Profissional, elaborado pelo Sindicado Nacional dos Auditores Fiscais do Trabalho (SINAIT, 2019).

Também foram sugeridas capacitações para auxiliar a ambientação do jovem nas empresas. Nessa direção, afirma Lacombe (2005) que habitualmente a capacitação ocorre no dia a dia, com aprendizado de tarefas, orientações da chefia; estabelecimento de metas, rodízio de funções, mentorias ou tarefas especiais.

\section{PERMANÊNCIA E DESLIGAMENTO DO JOVEM APRENDIZ}

A permanência do jovem se dá de forma concomitante na empresa e no Senac (local em que ocorre o processo de formação técnico-profissional). Esta formação deve ser constituída "por atividades teóricas e práticas, organizadas em tarefas de complexidade progressiva, em programa correlato às atividades desenvolvidas nas empresas contratantes, proporcionando ao aprendiz uma formação profissional básica" (BRASIL, 2011, p. 9).

Durante o período de permanência do jovem no Programa, o qual pode durar até dois anos, conforme o artigo 45 da lei 9579/18, este deve desenvolver habilidades e competências relacionadas à profissionalização. Tal processo deve ser compatível com o desenvolvimento físico, moral e psicológico do aprendiz, considerando "as demandas e diversidades dos adolescentes, em sua condição peculiar de pessoa em desenvolvimento, dos jovens, do mundo de trabalho e da sociedade quanto às dimensões ética, cognitiva, social e cultural do aprendiz (BRASIL, 2011, p. 9).

O aprendiz, a partir do momento em que ingressa no Programa, passa a ser avaliado pela empresa, pelo Senac e ainda pela Escola regular, que ele continua frequentando, o que traz implicações tais como a apontada por Rockenbach (2015, p. 64):

Uma questão importante é que os jovens aprendizes estão na condição de alunos duplamente: na escola e na instituição de ensino. Mesmo que na educação profissional se busque promover práticas que simulem as futuras atividades na empresa, os jovens ainda estão no ambiente de sala de aula e sujeitos ao disciplinamento que isso envolve.

O disciplinamento envolvido na empresa e no Senac acabam por determinar ao jovem mudanças de rotina, estilos e atitudes. Essas mudanças visam a formação do profissional para o mercado de trabalho. Sobre essas formas de expressão da juventude, de que os aprendizes precisam abrir mão para ingressar no "mundo do trabalho", Dayrell (2003, p. 51) destaca que: "[...] a vivência do estilo possibilitou, aos jovens, práticas, relações e símbolos por meio dos quais se afirmaram com uma identidade própria como jovens. Enfim, o estilo se coloca como mediador de um determinado modo de ser jovem".

No entanto, durante o período de permanência, o jovem deve se adequar às normas do Senac e da empresa, criando uma imagem profissional considerada adequada por/para estes espaços. Isso implica em adaptar a maneira de se vestir e se comportar, preservar determinados cortes de cabelo, não deixar piercings e tatuagens à mostra, uma vez que normas não cumpridas também podem levar ao desligamento do jovem do Programa. 
Pode-se dizer que a formação do jovem aprendiz é muito mais exigente em relação a postura e comportamentos do que na escola regular devido as exigências do mercado de trabalho. Não são tolerados bonés, minissaias, decotes, regatas e aparelhos eletrônicos em geral (o que na escola pode ser admito durante negociação) (ROCKENBACK, 2015, p. 63).

Entre os anos de 2014 e 2018, aproximadamente 1.500 jovens foram matriculados no PJA do Senac Chapecó, dos quais $5 \%$ evadiram e $10 \%$ reprovaram (a maioria por frequência, já que cada Unidade Curricular ${ }^{1}$ necessita de $75 \%$ de presença). Na discussão do GET, foram apontados os principais aspectos que se apresentam como desafios para a permanência dos aprendizes: a) impacto da responsabilidade da rotina da vida adulta, que vem com a inserção no PJA, b) aliar estudos ao primeiro emprego, e c) a adaptação com as regras e tarefas a serem executas durante o Programa de Aprendizagem.

De acordo com Borges (2010), os motivos relacionados à inserção do jovem no Programa de Aprendizagem giram em torno de expectativas como autonomia financeira, trabalho estável e cursar nível superior. Vale ressaltar que muitos jovens buscam se manter no estágio com a intenção de ser contratados ou ter boas referências no currículo para conseguir recolocação no mercado de trabalho ao final do Programa.

\begin{abstract}
Ao jovem aprendiz é sempre frisada a necessidade de um bom currículo que começa é claro, pelo Programa de Aprendizagem Profissional. Lembra-se que o desligamento do curso implica em demissão da empresa, logo isso será registrado na carteira de trabalho. Ser desligado não é algo bom para o currículo. Dessa forma, o jovem se vê impelido a continuar, mesmo que não deseje atuar na Área do comércio, por exemplo. Afinal, um desligamento implica em "sujar" a carteira de trabalho (ROCKENBACH, 2015, p. 69).
\end{abstract}

Permanecer no PJA também implica em reorganizar o tempo, mudar atitudes, assumir novas e, às vezes, maiores responsabilidades. Corrobora, com isso, Silva (2018, p. 7), que afirma que: "O trabalho é visto pelos jovens como uma forma de inserção a um mercado cada vez mais difícil de se inserir e ainda engloba um conjunto de aprendizado e responsabilidades".

Durante o período de permanência no PJA, os jovens tendem a sentir mais cansaço físico e mental em relação às cobranças exercidas na Empresa, no Senac e na Escola. Isso ocorre, pois, entram em uma rotina diferente da qual estavam acostumados, sobrando menos tempo para o lazer com família e os amigos. A diminuição do tempo de lazer pode ser um dos reflexos do aumento de responsabilidade, provocando vivências contraditórias nos jovens aprendizes, como acena Borges (2010, p. 118):

\footnotetext{
A partir do início da primeira experiência profissional, também principiam transições para vida adulta. Assim, passam a dispor de menos tempo livre e ambiguamente, significam esse momento, ora como perda de horários de lazer, ora ganhos de independência e amadurecimento pessoal.
}

Para Souza et al. (2017), uma das atitudes referentes ao trabalho, ou adquiridas por meio deste, é a responsabilidade, com mais obrigações, cobranças, tarefas e horários a cumprir. As observações de campo, corroboradas pelas discussões do GET, apontam que os turnos em que ocorre o programa, matutino e vespertino, impactam no desempenho escolar dos jovens aprendizes. Nesse sentido, os alunos que se inserem nas empresas no período matutino, pela falta de acesso ao Ensino Médio no turno vespertino, acabam migrando para o ensino noturno. Esses alunos apresentam, de forma geral, maior número de faltas e reprovações do que os que conseguem frequentar a escola no período matutino. Esses aspectos, juntamente à mudança de rotina e ao cansaço, foram identificados pelo GET como os principais motivos para desistência dos jovens do programa.

Nessa direção, afirma P3:

Eu percebo a diferença nos alunos do turno matutino e vespertino. Talvez, pela mudança radical de horário, pois muitos precisaram mudar para o turno da noite na escola, e, geralmente, estão cansados nas aulas e apresentam dificuldade de organizar seus horários e manter os compromissos (P3).

\footnotetext{
${ }^{1}$ As unidades curriculares são divididas em 60 horas, 36 horas, 84 horas dependendo a competência a ser desenvolvida.
} 
Vale destacar que o jovem pode solicitar o desligamento do programa ou a empresa poderá desligálo antes do término do contrato. As formas de desligamento do jovem, conforme o artigo 433, do decreto Lei 5.452/1943, podem ocorrer diante de tais circunstâncias: I - Desempenho insuficiente ou inadaptação do aprendiz; II - Falta disciplinar grave; III - Ausência injustificada à escola que implique perda do ano letivo; IV - A pedido do aprendiz.

Na resposta ao questionário, $16,7 \%$ das empresas dizem que a dificuldade em conciliar trabalho e estudo é o principal motivo que determina o desligamento dos jovens aprendizes, quando este se dá a pedido dos mesmos. Os outros motivos seriam: a) outra proposta de trabalho $(33,3 \%)$, b) mudança de cidade $(5,6 \%)$, c) problemas familiares $(5,6 \%)$ e d) outros motivos (38,9\%). Ao explicar quais seriam os outros motivos, os gestores de Recursos Humanos elencam questões como “Depende do perfil do jovem. Alguns não aguentam a pressão do trabalho" (E4). Outros respondentes destacam a remuneração como principal questão: "a maioria procura empregos onde possam atuar o dia inteiro" (E5), ou ainda: "quando parte deles, é porque já podem ter um trabalho remunerado e com renda maior" (E6).

Avalia-se que a realização de entrevistas de desligamento poderia contribuir para a compreensão dos motivos de desligamento dos jovens da empresa. Esta, já é realizada por $50 \%$ das empresas respondentes. Sobre os benefícios das entrevistas de desligamento, Chiavenato $(2009$, p. 40) aponta que:

Devido à rotatividade existente, algumas empresas utilizam a entrevista de desligamento como instrumento investigativo. A partir de entrevistas ou questionários aplicados, podem ser avaliadas e identificadas as causas que influenciam a alta rotatividade geralmente expressos por meios percentuais entre admissões e desligamentos quase sempre com essa rotatividade apresentada como índices mensais ou anuais para permitir comparações.

Assim, a ferramenta da entrevista de desligamento poderia contribuir para identificar os principais motivos que levam os aprendizes a desistirem de participar do Programa. Já, quando o desligamento do jovem ocorre a pedido da empresa, os principais motivos elencados são: problemas de comportamento $(61,1 \%)$, absenteísmo do jovem $(11,1 \%)$, desempenho ruim nas atividades $(5,6 \%)$ e outros motivos $(22,2 \%)$. Ao responderem o questionário, $94,4 \%$ das empresas consideram que o tipo de tarefas desempenhadas influencia na permanência dos jovens aprendizes e 5,6\% entendem que não influencia.

Ao encontro da avaliação das empresas, Rockenbach (2015) aponta que alguns jovens desistem dos Programas de Aprendizagem por não gostarem das atividades que desenvolvem na empresa, como, por exemplo, empacotar mercadorias. No entanto, o autor destaca que muitos jovens, mesmo não concordando com as normas ou não gostando das atividades realizadas, permanecem no programa devido às questões financeiras.

A falta de motivação dos jovens para o trabalho é apontada por várias empresas como a principal dificuldade que enfrentam em relação aos jovens do PJA. Nesse sentido, quando questionadas sobre que ações realizam com os jovens aprendizes, com vistas a motivar os mesmos para o trabalho, as empresas destacaram, especialmente, a utilização de avaliações e feedbacks (44\%), diversidade nas tarefas realizadas, o que é promovido por 38,9\% dos respondentes, 33,3\% diversificam os setores onde o jovem vai atuar, mas os mantêm em tarefas rotineiras e 11,1\% mantêm os jovens no mesmo setor, fazendo tarefas fáceis do dia a dia.

Ao comentarem sobre as ações voltadas à motivação do jovem para permanência no PJA, uma das empresas aponta para a necessidade de: “Desenvolver uma avaliação com os jovens de como está o desenvolvimento deles no trabalho e o que, na visão deles, poderia ser melhorado no ambiente de trabalho para melhorar seu desempenho" (E2).

Na mesma direção, outra empresa destaca o diálogo como principal ação: "Muito diálogo com os jovens, demonstrando a importância do trabalho e do aprendizado no curso oferecido pelo Senac"(E7). Já, na compreensão do GET, a diversidade nas tarefas realizadas é o que mais motivaria os jovens à permanência no PJA.

É fundamental que tanto a empresa quanto o jovem tenham conhecimento das atividades que podem ser desempenhadas na organização para poder diversificar as mesmas durante a permanência desse. Durante o segundo debate do GET, ao abordar questões sobre as atividades executadas pelo jovem, E2 
informou que "Algumas empresas desconhecem as atividades que podem ser adaptadas e/ou ensinadas para ao aprendiz". A partir deste comentário, percebe-se uma falha de comunicação entre o Senac e as empresas, que precisa ser enfrentada.

Ao avaliarem a possibilidade de incorporar o jovem à empresa, ao final do PJA, 38,9\% dos respondentes avaliam como ótima, e 50\% como boa, 5,6\% das empresas respondentes que avaliaram a possibilidade de contratação do jovem como regular e $5,6 \%$ como ruim. Sobre isso, uma gestora de RH aponta que "quando surge uma oportunidade na empresa de acordo com seu perfil, ocorre a contratação do jovem. Atualmente a empresa preza pela efetivação deles no quadro de pessoal" (E8). Isso se deve a dois fatores: ao bom desempenho do jovem e a adequação ao perfil desejado para empresa, o que, de acordo com Silva (2018) confirma uma política administrativa em que "[...] os iniciantes podem ser moldados de acordo com os interesses da organização.

\section{QUALIFICANDO A INSERÇÃO E PERMANÊNCIA DO JOVEM NO PJA: CONSIDERAÇÕES A PARTIR DO CAMPO}

Moura (2018) afirma que seria relevante o acompanhamento a longo prazo do Governo Federal em relação à permanência e ao desligamento do jovem aprendiz. Na empresa, a Lei da Aprendizagem prevê uma pessoa responsável pelo acompanhamento do jovem aprendiz no exercício das atividades práticas, denominada monitora.

\footnotetext{
O monitor ficará responsável pela coordenação de exercícios práticos e acompanhamento das atividades do aprendiz no estabelecimento, buscando garantir sempre uma formação que possa de fato contribuir para o seu desenvolvimento integral e a consonância com os conteúdos estabelecidos no curso em que foi matriculado, de acordo com o programa de aprendizagem (art. 23, § 10, do Decreto Lei no 5.598/05, BRASIL, 2005).
}

O manual do aprendiz também estabelece que "a entidade formadora deverá fornecer à empresa o respectivo plano de curso e orientá-la para que ela possa compatibilizar o desenvolvimento da prática à teoria ministrada" (BRASIL, 2011, p. 14). No entanto, o Senac de Chapecó oferece, conjuntamente, um outro responsável, que acompanha o jovem durante todo o processo de permanência no Programa, denominado Professor de Vivência. Este se torna um professor de referência por turma do PJA, já que os mesmos fazem visitas às empresas, assim como avaliam e acompanham o jovem durante o Programa.

O jovem é avaliado trimestralmente pela empresa, por meio de um formulário desenvolvido pelo Senac e preenchido pelo Professor de Vivência. Esse procedimento ocorre durante as visitas, onde avalia-se o desempenho do aprendiz, e é baseado no desenvolvimento das competências e atitudes elencadas no plano de curso. Esta avaliação de desempenho do jovem é positiva ou negativa, de acordo com a adequação dele em relação às tarefas e às atitudes, tais como: proatividade, comprometimento quanto a faltas e atrasos, postura profissional adequada às exigências do mercado de trabalho etc.

Essa ferramenta procura enquadrar o jovem no perfil profissional desejado pela empresa. A partir desta avaliação de desempenho, o Professor de Vivência faz devoluções ao jovem sobre o que precisa ser adequado para atender às necessidades da empresa. Observa-se no campo que muitos aprendizes se decepcionam com as avaliações, pois não entendem algumas críticas, o que indica a necessidade de melhorar a comunicação entre a empresa e o jovem. Um maior acompanhamento do Professor de Vivência, em relação ao jovem, familiares do mesmo e a empresa, juntamente ao Senac, também foi apontado pelo GET como uma alternativa para diminuir os desligamentos dos jovens e melhorar o processo de inserção e permanência.

Destaca-se que, ao analisar a parceria entre as empresas e o Senac de Chapecó, $72,2 \%$ das empresas respondentes aos questionários avaliam essa como boa, $22,2 \%$ como ótima e 5,6\% como regular. De todo modo, esta parceria poderia ser qualificada com diferentes ações que teriam impacto sobre a permanência do jovem aprendiz.

No sentido de melhorar a comunicação entre o Senac e a empresa, também é possível descrever para a empresa e pais como o jovem está se desenvolvendo no aprendizado do programa. Para os pais, é relevante que saibam se o jovem está se desenvolvendo com qualidade no programa. Já, para os gestores de RH ou 
responsáveis pelo jovem aprendiz, na empresa, é importante anunciar os conhecimentos, as habilidades e as atitudes que estão sendo desenvolvidas durante o curso no Senac. Assim, ficará mais fácil para os jovens associarem a teoria à prática.

Foi ainda levantado, no primeiro e segundo encontro do GET, a importância do jovem/familiares e empresa conhecerem o perfil de conclusão de curso, sendo esse, atualmente, informado pelo Senac aos jovens nos primeiros dias do curso. Tanto as empresas quanto os pais, ao terem essa informação, poderiam, segundo os participantes, conduzir melhor o jovem, de acordo com o que o perfil de conclusão do curso requer.

O GET concluiu, no debate, de que a presença dos pais é de suma importância para a efetividade do Programa Jovem Aprendiz, na seleção, no desenvolvimento do Programa e na finalização dele. Isso vai ao encontro do que propõe Porto e Soares (2019, p. 32), ao afirmarem que "é importante a participação da família, trazendo tranquilidade a todos envolvidos". Vale lembrar que, no caso do jovem aprendiz ser menor de 18 anos, é obrigatória a assinatura dos pais para concretizar o contrato de trabalho, assim como todas as ações do jovem que impliquem em penalização também são, por força de lei, de responsabilidade dos pais. É nesse momento que deve ser explicado aos pais e ao jovem sobre as atividades e suas finalidades, sendo essa uma sugestão para o melhor entendimento das tarefas que serão desenvolvidas no decorrer do programa.

Tendo em vista a necessidade de qualificar a comunicação entre o Senac e as empresas para melhorar a gestão do PJA, sugeriu-se, a partir do GET, a produção de material didático específico, uma cartilha, com orientações para fazer o recrutamento, seleção e integração do jovem, que pudesse ser uma referência para as empresas participantes do Programa, bem como para os Professores de Vivência. Essa cartilha deve ser baseada nas normativas do CONAP e da CBO, no que tange à descrição das funções para o jovem aprendiz. Vale destacar que há guias para a implementação de Programas de Aprendizagem, como aquelas criadas pelo Conselho Nacional do Ministério Público (2012), do Manual de Aprendizagem do antigo Ministério do Trabalho e Emprego (2014), o Manual do Programa Aprendiz do CIEE e do Manual do Sindicato Nacional dos Auditores Fiscais do Trabalho (2019), as quais podem referenciar o material didático.

Para além de material didático, esse processo pode ser melhorado por meio da mediação do Professor de Vivência junto ao responsável pelo jovem aprendiz na empresa e junto às famílias. A figura desse profissional é uma das potencialidades do PJA oferecidas pelo Senac, mediação esta que ocorre durante as visitas à empresa, por meio de contatos por e-mail ou telefone. O Senac ainda poderá contribuir com a capacitação dos trabalhadores responsáveis pelos jovens aprendizes com o intuito de qualificar o processo de inserção e permanência dos jovens no PJA.

Outra ação que poderia ser implementada é a criação de espaços para troca de experiências entre as empresas. Nesse sentido, 55,6\% das empresas respondentes ao questionário afirmaram que participariam de seminários de socialização sobre experiências exitosas relacionadas ao PJA e 44,4\% que não participariam. Essa comunicação/troca poderia ser proposta na reunião com as empresas, que ocorre no início do PJA.

\section{CONSIDERAÇÕES FINAIS}

Esta pesquisa teve como foco o processo de inserção e permanência junto às empresas, dos jovens que fazem o PJA. Desde a sua criação, o Programa de Aprendizagem resistiu às mudanças de governo, adequando-se as novas realidades e incorporando o direito do emprego legalizado e seguro para a juventude. Mesmo com todos os ajustes que essa política pública sofreu ao longo dos anos, ainda é observada a necessidade de aprimoramento.

Os resultados apontam que a inserção e permanência dos jovens nas empresas, compreende realidades muito distintas. Isso inclui desde a realização de processos de seleção e integração, assim como suporte para a permanência dos alunos, até contextos em que a presença dos jovens é vista como mera obrigação legal, e/ou em que não há estratégias para auxiliar o ingresso e permanência desses.

Tendo em vista ser uma pesquisa-ação, com vistas à transformação da realidade estudada, o Grupo Estratégico de Trabalho sugeriu várias ações para qualificar o Programa Jovem Aprendiz oferecido pelo Senac de Chapecó. Entre as mesmas, promover maior acompanhamento aos jovens, por meio do Professor de Vivência do Senac, com vistas a qualificar a comunicação com a família e o responsável pelo jovem na empresa. 
Ainda, utilizar a ferramenta da cartilha (apoiada em vídeos e/ou material ilustrativo) em que estejam claros: o perfil de conclusão de curso, as instruções quanto à ficha de anamnese, o roteiro para entrevista de desligamento e a avaliação do jovem aprendiz.

É necessário também promover estratégias que produzam um maior engajamento das empresas, quanto ao desenvolvimento do aprendiz, considerando a responsabilidade dessas frente ao primeiro emprego dos jovens. Para isso, espaços para troca de experiências exitosas mobilizados pelo Senac também poderiam contribuir.

Por fim, destaca-se que o objetivo desta política pública não se limita a inserir os jovens no mercado de trabalho a qualquer custo, mas de forma qualificada, promovendo experiências que possam ampliar as capacidades cognitivas, afetivas e técnicas dos jovens. Assim, sugere-se novos estudos que possam pensar as singularidades das empresas de diferentes segmentos que participam do PJA, na perspectiva de qualificar o Programa.

\section{REFERÊNCIAS}

BORGES, R. C. P. Jovem-aprendiz: os sentidos do trabalho expressos na primeira experiência profissional. 2010. Dissertação (Mestrado em Psicologia)-Centro de Filosofia e Ciências Humanas, Universidade Federal de Santa Catarina, Florianópolis, 2010.Disponível em:

https://repositorio.ufsc.br/xmlui/bitstream/handle/123456789/93666/280625.pdf?sequence=1\&isAllowed=y. Acesso em: 29 jun. 2021.

BIOLCHINI, C.; PIMENTA, M.; OROFINO, M. A. Ferramentas visuais para estrategistas: cocriação. 2012. Disponível em:

https://www.academia.edu/29883178/VISUAIS_PARA_ESTRATEGISTAS_COCRIA\%C3\%87\%C3\%830_17_COL ABORADORES. Acesso em: 29 jun. 2021.

BRASIL. Ministério do Trabalho e Emprego. Secretaria de Inspeção do Trabalho. Manual de aprendizagem: o que é preciso saber para contratar o aprendiz. 7. ed. Brasília, DF: MTE, 2011. Disponível em:

https://enit.trabalho.gov.br/portal/images/manuais/Manual_de_Aprendizagem_verrao_para_download.pd f. Acesso em: 02 jun. 2021.

BRASIL. Decreto n. 5.598, de 1 de dezembro de 2005. Regulamenta a contração de aprendizes e dá outras providências. Brasília, DF: Casa Civil, 2005. Disponível em: http://www.planalto.gov.br/ccivil_03/_Ato20152018/2018/Decreto/D9579.htm\#art126. Acesso em: 29 jun. 2021.

CASTRO, J. A.; AQUIN, L. M. C.; ANDRADE, C. C. Juventude e políticas sociais no Brasil. Brasília: Ipea, 2009. Disponível em: https://www.ipea.gov.br/portal/images/stories/PDFs/livros/livro_juventudepolitica.pdf. Acesso em: 02 jun. 2021.

CHIAVENATO, I. Planejamento, recrutamento e seleção de pessoal. Rio de Janeiro: Manole, 2009.

DAYRELL, J. O jovem como sujeito social. Revista Brasileira de Educação, São Paulo, n. 24, p. 40-52, 2003. Disponível em: https://www.scielo.br/j/rbedu/a/zsHS7SvbPxKYmvcX9gwSDty/?format=pdf\&lang=pt. Acesso em: 29 jul. 2021.

DIONNE, H. A pesquisa-ação para o desenvolvimento local. Tradução de Michel Thiollent. Brasília: Líder Livro, 2007.

FERREIRA, S. F.; SOEIRA, F. S. A. A importância do recrutamento e seleção de pessoas em uma empresa de pequeno porte do setor de móveis. Diálogos Acadêmicos, Fortaleza, v. 4, n. 1, p. 46-56, 2013. Disponível em: http://uniesp.edu.br/sites/_biblioteca/revistas/20170627111419.pdf. Acesso em: 02 jun. 2021.

GALDINO, L. A. Competências profissionais discentes: um estudo de caso no Programa Jovem Aprendiz. Campina Grande:UFCG, 2018. Disponível em:

http://dspace.sti.ufcg.edu.br:8080/jspui/bitstream/riufcg/5318/1/LARYSSA\%20DAMIANY\%20DE\%20ALMEID A\%20GALDINO\%20-\%20TCC\%20ADMINISTRA\%c3\%87\%c3\%830\%202018..pdf. Acesso em: 02 jun. 2021. 
LACOMBE, F. J. M. Recursos humanos: princípios e tendências. São Paulo: Saraiva, 2005.

MACHADO, M. P. M; PASSOS, M. F. D. O uso do World Café como método de pesquisa junto às equipes de saúde. Revista Brasileira em Promoção da Saúde, Fortaleza, v. 31, p. 1-10, 2018. Suplemento. Disponível em: https://periodicos.unifor.br/RBPS/article/viewFile/8647/pdf. Acesso em: 28 jun. 2021.

MATSUZAKI, H. H. O desafio da lei do Jovem Aprendiz: um estudo e aplicação da lei 10.097/00 como política pública de inclusão de jovens no ambiente de trabalho. 2011. Dissertação (Mestrado em Administração) - Faculdade de Economia, Administração e Contabilidade, Universidade de São Paulo, São Paulo, 2011. Disponível em: https://www.teses.usp.br/teses/disponiveis/12/12139/tde-01122011185435/publico/HugoHidemiMatsuzaki.pdf. Acesso em: 02 jun. 2021.

MOURA, L. S. Juventude e trabalho: o perfil do jovem aprendiz da Rede Pró-Aprendiz-GO. 2018. Tese. (Doutorado em Sociologia) — Faculdade de Ciências Sociais, Universidade Federal de Goiás, Goiânia, 2018. Disponível em: https://repositorio.bc.ufg.br/tede/bitstream/tede/8803/5/Tese\%20\%20Leila\%20Silva\%20de\%20Moura\%20-\%202018.pdf. Acesso em: 29 jun. 2021.

NERI, M. C. Onda jovem na educação profissional: determinantes e motivações. In:CORSEUIL, C. H.; BOTELHO, R. U. (org.). Desafios à Trajetória Profissional dos Jovens Brasileiros. Rio de Janeiro: Ipea, 2014. p. 21-72. Disponível em: https://www.ipea.gov.br/portal/images/stories/PDFs/livros/livros/livro_desafios_completoweb.pdf. Acesso em: 29 jun. 2021.

PEREIRA, D. G.; SPÍNDOLA, J. Análise compreensiva da inserção no mercado de trabalho através do primeiro emprego: ser-jovem aprendiz. REH - Revista de Educação e Humanidades, Manaus, v. 1, n. 2, p. 457-477, dez. 2020. Disponível em: https://periodicos.ufam.edu.br/index.php/reh/article/view/7934/5651. Acesso em: 02 jun. 2021.

PESSOA, M. C. B. Política de formação profissional e contextos sociais: trajetória e projeto de da vida dos jovens. 2017. Tese (Doutorado em Psicologia Social) — Centro de Ciências Humanas e Letras, Universidade Federal da Paraíba, João Pessoa, 2017. Disponível em: https://repositorio.ufpb.br/jspui/bitstream/tede/9132/2/arquivototal.pdf. Acesso em: 02 jun. 2021.

PFAFFENSELLER, C. A formação de jovens para o mundo do trabalho a partir da Lei da Aprendizagem. 2014. Dissertação (Mestrado em Educação) — Faculdade de Educação, Universidade Federal do Rio Grande do Sul, Porto Alegre, 2014. Disponível em: https://www.lume.ufrgs.br/handle/10183/106498. Acesso em: 29 jun. 2021.

POCHMANN, M. A batalha pelo primeiro emprego: a situação atual e as perspectivas do jovem no mercado de trabalho brasileiro. 2. ed. São Paulo: Publisher Brasil, 2007.

PORTO, A. S.; SOARES, V. D. Ações de acolhida em programas de integração para o jovem aprendiz. Revista Metodista de Administração do Sul, Porto Alegre, v. 4, n. 6, p. 3-3, 2019. Disponível em: https://www.metodista.br/revistas/revistas-ipa/index.php/administracao/article/view/805/733. Acesso em: 29 jun. 2021.

PRATO NETO, C.; MIRANDA, B. S.; SILVA, R. W.; FIGHEIRA, L. M.; MARTINELLI, M.; PENTIADO, L. G. A importância do processo de recrutamento e seleção de pessoas na retenção do capital intelectual. Revista Espacios, Caracas, v. 37, n. 32, p. 1-1, 2016. Disponível em: http://www.revistaespacios.com/a16v37n32/16373213.html. Acesso em: 02 jun. 2021. Acesso em: 29 jun. 2021.

ROCKENBACH, D. R. Jovens aprendizes contemporâneos - "eu acredito é na rapaziada": problematizando o programa jovem aprendiz. 2015. Dissertação (Mestrado em Educação) — Faculdade de Educação, Universidade Federal do Rio Grande do Sul, Porto Alegre, 2015. Disponível em: http://www.lume.ufrgs.br/handle/10183/131052. Acesso em: 02 jun. 2021.

SENAC. Plano de curso: aprendizagem profissional comercial em serviços administrativos. Florianópolis: Departamento Regional, 2014. 
SILVA, G. M. S. A difícil realidade do jovem aprendiz para inserção no mercado de trabalho. In:CONGRESSO INTERNACIONAL DE TECNOLOGIA NA EDUCAÇÃO, 16., 2018, Pernambuco. Anais [...]. Olinda: Senac, 2018. p. 1-8. Disponível em: http://www.pe.senac.br/congresso/anais/2018/pdf/comunicacaooral/A\%20DIF\%C3\%8DCIL\%20REALIDADE\%20DO\%20JOVEM\%20APRENDIZ\%20PARA\%20INSER\%C3\%87\%C 3\%830\%20NO\%20MERCADO\%20DE\%20TRABALHO.pdf. Acesso em: 29 jun. 2021.

SILVA, L. N.; NASCIMENTO, R. F.; BOTELHO, M. A. S. A importância do programa de interação: um estudo da perspectiva dos gestores da empresa Lopes \& Cia. In: SIMPÓSIO DE EXCELÊNCIA EM GESTẪO E TECNOLOGIA, 10., 2013, Rio de Janeiro. Anais [...]. Rio de Janeiro: Dom Bosco, 2013. p. 1-14.

SINAIT. Manual da aprendizagem profissional: o que é preciso saber para contratar um aprendiz. Brasília: SINAIT, 2019. Disponível em:

https://enit.trabalho.gov.br/portal/images/manuais/Manual_de_Aprendizagem_versao_para_download.pd f. Acesso em: 02 jun. 2021.

SOUZA, D. A.; MELO, S. F.; FAJAN, F. D.; NABARRO, C. B. M.; OLIVEIRA, M. A. M. A percepção dos jovens aprendizes sobre o trabalho que exercem. In: SIMPÓSIO DE EXCELÊNCIA EM GESTÃO E TECNOLOGIA, 13. 2017, Rio de Janeiro. Anais [...]. Rio de Janeiro: Dom Bosco, 2013. p. 1-16. Disponível em: https://www.aedb.br/seget/arquivos/artigos17/12425153.pdf. Acesso em: 29 jun. 2021.

TRIPP, D. Pesquisa-ação: uma introdução metodológica. Educação e Pesquisa, São Paulo, v. 31, n. 3, p. 443466, 2005. Disponível em: http://www.scielo.br/pdf/ep/v31n3/a09v31n3.-pdf. Acesso em: 02 jun. 2021.

VILLAR, C. O.; MOURÃO, M. L. Avaliação do Programa Jovem Aprendiz a partir de um Estudo QuaseExperimental. Trends Psychol, [S. I.], v. 26, n. 4, p. 1999-2014, 2018. Disponível em: https://www.scielo.br/j/tpsy/a/rPjRTBBXYK3Q9jhnNLNYvqx/abstract/?lang=pt. Acesso em: 29 jun. 2021. 